Published in Topics in Catalysis, vol. 50, pp. 222-286 (2008)

The original publication is available at www.springerlink.com

http://www.springerlink.com/content/r547x728457h0653/

\title{
INFLUENCE OF AL DISTRIBUTION AND DEFECTS CONCENTRATION OF FERRIERITE CATALYSTS SYNTHESISED FROM Na-FREE GELS IN THE SKELETAL ISOMERISATION OF N-BUTENE.
}

Authors: C. Márquez-Alvarez, A.B. Pinar, R. García, M. Grande-Casas and J. PérezPariente*

Instituto de Catálisis y Petroleoquímica, CSIC, C/Marie Curie 2. Cantoblanco, 28049Madrid, Spain

* e-mail: jperez@icp.csic.es

\begin{abstract}
The skeletal isomerisation of n-butenes to isobutene has been carried out over ferrierite catalysts $(\mathrm{Si} / \mathrm{Al} \sim 15)$ containing different acid sites distribution and different amount of defects. The zeolite crystals were synthesised under hydrothermal conditions in fluoride medium in the absence of alkaline cations by using suitable combinations of structure directing agents. Template-driven low density of acid sites in 10-membered-ring channels enhances the isobutene selectivity and decreases catalyst deactivation. The presence of high amount of silanol groups and Lewis acid sites increases the yields of by-products and catalysts decay.
\end{abstract}

Keywords: Ferrierite; zeolite synthesis; fluoride medium; Al sitting; acid sites distribution; FTIR; pyridine; isomerisation; 1-butene, isobutene

\section{INTRODUCTION}

The skeletal isomerisation of linear butenes to isobutene catalyzed by the zeolite ferierrite has been much investigated since its noticeable performance in this reaction was reported in 1990s [1-3]. A substantial number of contributions focuses on 
mechanistic aspects of this reaction, for unimolecular and bimolecular mechanism have been proposed to take place inside the zeolite channels and to yield different products, in particular isobutene [4-9], on the deactivation mechanism of the reaction, as the selectivity to the targeted isobutene strongly enhances with time-on-stream and hence with catalyst deactivation [10-12], and on the contribution of the number, type and location of acid sites. Indeed, Brönsted acid sites can be located in different positions in the framework, either in the 10-MR channel or in the ferrierite cage accessible through 8-MR windows [13-16] and, moreover, the contribution of extra-framework Lewis acid sites has also been studied [17-19].

All these contributions reflect the complex nature of the reaction, and the combination of several factors that lead finally to selective catalysts. Among them, the location and type of acid sites seems to play a determinant role in the isobutene yield and in the deactivation process. A number of studies on the location of acid sites in $\mathrm{H}$-ferrierite evidence that the protons are associated to framework oxygen atoms located at specific positions, which, together with the studies on adsorption of $\mathrm{CO}$ on $\mathrm{Li}$-exchanged samples [20] point to a non-random distribution of Al in the framework. However, we have found recently evidences that the Al location in the framework can be influenced by the nature of the template used in the synthesis when this is carried out in the absence of sodium cations $[21,22]$. Different combinations of templates such as 1benzyl-1-methyl-pyrrolidinium, pyrrolidine and tetramethylammonium led to samples exhibiting large differences in the fraction of Brönsted acid sites accessible to pyridine, which strongly affects the activity of these samples in acid-catalyzed reactions such as isomerisation/disproportionation of m-xylene and n-butene isomerisation. 
An additional factor to take into account in determining the activity and selectivity of ferrierite catalysts arises from the potential presence of a high concentration of silanol groups as a function of specific synthesis conditions. In regard to this, it is worth mentioning that relatively well-defined crystalline layered aluminosilicate known as PREFER has been isolated and described, which led to three-dimensional ferrierite by condensation upon heating [23]. Mismatching of consecutive layers by shifting them along the plane perpendicular to the layer stacking prevents full condensation of all the available terminal $\mathrm{SiOH}$ groups present at the layer surface, which remain hence as connectivity defects in the final, partially condensed material. The so-called PREFER can be considered as an end-member of a family of layered materials related to ferrierite, to which many different materials with divers degree of layer condensation belong to, such as MCM-47, the borosilicate ERS-12 or the UZM series of materials [24-26].

We have reported elsewhere on the synthesis of ferrierite materials possessing different degree of layer condensation, and hence different concentration of connectivity defects (uncondensed $\mathrm{SiOH}$ groups), crystallised by using a proper combination of several cage-forming and channel-forming co-structure directing agents [27, 28]. Those synthesis procedures made available ferrierite crystals possessing various degrees of connectivity defects, which allow exploring in a systematic way the influence of this parameter on the skeletal isomerisation of n-butene. In this work, the study of the catalytic behaviour of these samples will be complemented with that of low-defect samples described above and reported elsewhere [21], which contain a non-random distribution of acid sites also obtained by appropriate choice of co-structure directing agents. 


\section{EXPERIMENTAL}

\section{Zeolite synthesis}

Zeolites were synthesised from gels of molar composition: $0.06 \mathrm{Co}-\mathrm{SDA}: 0.48 \mathrm{ROH}$ : $0.48 \mathrm{HF}: 0.03 \mathrm{Al}_{2} \mathrm{O}_{3}: 0.94 \mathrm{SiO}_{2}: 4.30-4.70 \mathrm{H}_{2} \mathrm{O}$ where $\mathrm{ROH}$ designates 1-benzyl-1methyl-pyrrolidinium (bmp) hydroxide or (S)-2-hydroxymethyl-1-benzyl-1methylpyrrolidinium (bmprol) hydroxide and co-SDA designates the corresponding costructure directing agent used in each preparation: tetramethylammonium (TMA) hydroxide (Aldrich, $25 \mathrm{wt} \%$ aqueous solution), quinuclidine (quin) hydrochloride (Aldrich, $97 \mathrm{wt} \%$ ), tetraethylammonium (TEA) hydroxide (Aldrich, $35 \mathrm{wt} \%$ aqueous solution). A sample prepared in the presence of pyrrolidine (pyrr) as the only SDA was crystallised from a gel with the same molar composition but with 0.54 moles of pyrrolidine (Aldrich, 99.5\%). The reagents were used without subsequent purification. In a typical preparation, $30.52 \mathrm{~g}$ of tetraethylorthosilicate (TEOS, Merck, $98 \mathrm{wt} \%$ ) and $1.93 \mathrm{~g}$ of aluminium isopropoxide (Fluka, $97 \mathrm{wt} \%$ ) were added to a solution containing $35.1 \mathrm{~g}$ of bmprol hydroxide and $3.3 \mathrm{~g}$ of tetramethylammonium hydroxide. The solution was left under stirring until the ethanol and the excess of water were evaporated. Subsequently, $3.06 \mathrm{~g}$ of HF (Panreac, $48 \mathrm{wt} \%$ ) were added dropwise. The resulting thick gel ( $\mathrm{pH} \sim 9.7)$ was homogenized and introduced into $20-\mathrm{mL}$ Teflon-lined stainless steel autoclaves, which were heated statically at $135^{\circ} \mathrm{C}$ under autogeneous pressure for selected periods of time. The solid products were recovered by filtration, washed with water and ethanol and dried at room temperature overnight.

The organic compounds occluded in the as-made crystals were removed by calcination. For this purpose, the zeolite samples were heated in $\mathrm{N}_{2}$ up to $200{ }^{\circ} \mathrm{C}$ and maintained at this temperature for $2 \mathrm{~h}$, followed by treatment with a flow of ozone/oxygen (60 
$\mathrm{mL} / \mathrm{min}$, ca. $2 \mathrm{vol} \% \mathrm{O}_{3}$ ) at $200{ }^{\circ} \mathrm{C}$ until complete removal of the organic material. Ozone in oxygen stream was produced using an ECO-5 ozone generator manufactured by SALVECO Proyectos S. L. Prior to their use in catalysis, the sample were heated in air for two hours till the temperature reached $550{ }^{\circ} \mathrm{C}$ and kept at that temperature for two hours.

A sample synthesised with pyrrolidine as SDA at high $\mathrm{pH}$ and in the presence of sodium cations was prepared following the procedure of Plank et al. [29]. It was ion-exchanged and calcined as described in reference [21].

The samples will be referred to with the name of the organic molecules employed as SDAs in each case, separated by a dash and followed by the duration of the hydrothermal treatment when it is necessary to specify it. As an example, FER-bmpquin-10d was obtained after crystallisation for 10 days using 1-benzyl-1-methylpyrrolidinium and quinuclidine as SDAs.

\section{Characterisation}

Solid products were characterised by XRD (PANalytical X'Pert PRO-MPD diffractometer. $\mathrm{CuK} \alpha$ radiation), thermogravimetric analysis (Perkin-Elmer TGA7 instrument, heating rate $20{ }^{\circ} \mathrm{C} / \mathrm{min}$, air flow $30 \mathrm{~mL} / \mathrm{min}$, temperature range $20-900{ }^{\circ} \mathrm{C}$ ), chemical CHN analysis (Perkin-Elmer $2400 \mathrm{CHN}$ analyzer) and SEM/EDX (Jeol JSM 6400 Philips XL30 operating at $20 \mathrm{kV}$ ). Nitrogen adsorption-desorption isotherms were measured at $-193{ }^{\circ} \mathrm{C}$ using a Micromeritics Tristar 3000 volumetric apparatus. Specific surface areas were calculated following the BET procedure.

FTIR spectra in the transmission mode were recorded in the $1000-4000 \mathrm{~cm}^{-1}$ range, at 4 $\mathrm{cm}^{-1}$ resolution, using a Nicolet 5ZDX and a ThermoNicolet Nexus 670 FTIR spectrometers provided with MCT detectors. The samples were pressed into self- 
supporting wafers (ca. $6 \mathrm{mg} / \mathrm{cm}^{2}$ thickness), placed in a glass cell with $\mathrm{CaF}_{2}$ windows, and activated in vacuum at $400{ }^{\circ} \mathrm{C}$ for $8 \mathrm{~h}$. Pyridine adsorption was carried out on activated samples kept at $150{ }^{\circ} \mathrm{C}$, and followed in dependence of time. The sample wafer was put in contact with pyridine vapour ( 8 Torr) at $150{ }^{\circ} \mathrm{C}$ for a given period of time, subsequently degassed at the same temperature for $30 \mathrm{~min}$, and then the FTIR spectrum was recorded. Pyridine was again dosed into the cell to allow further adsorption of the amine on the sample wafer, and the cell was evacuated for $30 \mathrm{~min}$ prior to recording the FTIR spectrum. This adsorption procedure was repeated several times in order to obtain a series of FTIR spectra at increasing total contact time of the sample wafer with pyridine. The spectra recorded after pre-treatment and after every pyridine adsorption step were normalised to a sample thickness of $6 \mathrm{mg} / \mathrm{cm}^{2}$. Difference spectra in the pyridine ring vibrations region were obtained by subtracting the spectrum of the pre-treated sample.

\section{Catalytic activity test}

The transformation of 1-butene was carried out in an automatic fixed-bed reactor under the following conditions: $400{ }^{\circ} \mathrm{C}$, atmospheric pressure, $\mathrm{N}_{2} /$ butene molar ratio $=4$, weight hourly space velocity $(\mathrm{WHSV})=25 \mathrm{~h}^{-1}$. The catalysts samples $\approx 100 \mathrm{mg}$ (pelletised and sieved to $0.42-0.84 \mathrm{~mm}$ ) were previously pre-treated in situ under nitrogen flow for 1 hour at $400{ }^{\circ} \mathrm{C}$. The products were analysed on-line by gas chromatography using a capillary column (PLOT $\mathrm{Al}_{2} \mathrm{O}_{3} 50 \mathrm{~m}$ x $530 \mu \mathrm{m}$ ). A Varian Cp3880 gas chromatograph provided with a flame ionisation detector (F.I.D.) was used in the analysis. The conversion into the different products was calculated by considering nbutene isomers as the reactant. 


\section{RESULTS AND DISCUSSION}

\section{Synthesis and bulk characterisation}

For the sake of clarity, the as-synthesised ferrierite samples have been classified into two different groups, according to their XRD pattern. These have been denoted as "Ferrierite-type materials" and "fully condensed ferrierite crystals", for samples having broad and poorly defined XRD peaks, in the first case, and those presenting a set of narrow peaks characteristic of conventional ferrierite crystals, for the latter.

\section{Fully condensed ferrierite crystals}

To study the effect of the combination of the different SDAs employed in the synthesis on the acid site distribution of the resulting materials, we carried out experiments using TMA+bmp, TMA+pyrrolidine and pyrrolidine alone in fluoride medium, and pyrrolidine in alkaline medium. Zeolite ferrierite was obtained in all these syntheses, as shown by the XRD patterns, although the FER-bmp-TMA sample presented somewhat broader diffraction peaks than the others. Scanning electron microscopy showed that these FER-bmp-TMA solids are composed by neddle-like crystals of about 7 microns in length, similar to those present in the ferrierite-type materials, as it will be shown below. By contrast, the samples obtained in the absence of bmp are composed of agglomerates of plate-like crystals. Differences in crystal size are observed among these samples. FER-pyrr and FER-pyrr-TMA samples possess crystals of about $22 \times 13$ microns, whereas those of FER1 sample prepared in alkaline medium have dimensions of about $2 \times 2.5$ microns. 
The $\mathrm{Si} / \mathrm{Al}$ ratio as measured by $\mathrm{SEM} / \mathrm{EDX}$ corresponds to an aluminium content of ca. 2.2 atoms per unit cell of ferrierite, without substantial differences between the several samples.

For the samples prepared with pyrrolidine or pyrrolidine and TMA, the resulting C/N ratio was 4 , close to the theoretical value corresponding to these molecules [21]. Chemical analysis and ${ }^{13} \mathrm{C}$ CP MAS NMR confirmed the integrity of TMA and bmp cations after the hydrothermal treatment for the FER-bmp-TMA samples [30].

Chemical analysis showed an organic content between 8.5 and $13 \mathrm{wt} \%$, depending on the molecules employed as SDAs in each case.

\section{Ferrierite-type of materials}

To study the role of the structure directing agents in the synthesis of ferrierite materials, we have systematically increased both the size of the large SDA and that of the smaller co-SDA. In a first set of experiments, the co-SDAs were varied using molecules of different sizes and shapes in preparations with bmp as the bulky SDA. Hence, the initial TMA cation was systematically substituted by a similar though bigger cation, TEA, and the cyclic bulkier amine quinuclidine. In a second step, to test the effect of a change in the large cation, bmp was replaced by a related although slightly bulkier cation, bmprol, in the preparation with TMA as a co-SDA.

Table 1 summarises the gel compositions and the products obtained in these preparations. The corresponding XRD patterns are depicted in Figure 1. The X-ray diffraction pattern of a sample of ferrierite synthesised with pyrrolidine (FER-pyrr-10d) corresponding to a fully condensed ferrierite material is also shown for comparative purposes. 
The diffraction patterns of all the samples are very similar and indicate that the products are related to the family of ferrierite layered materials. As commented in the introduction, these solids possess a structure made up by the stacking of ferrierite sheets along the direction perpendicular to the layer with the organic molecules used as SDAs located in the interlayer space. The different arrangement of the ferrierite sheets gives rise to the different members of this family of materials like PREFER [23] or MCM-47 [24].

The main difference among the XRD patterns of the as-synthesised products obtained in this study lays on the position of the first diffraction peak, which corresponds to the (200) planes of the structure and therefore is related to the interlayer distance. This distance varies with the specific combination of SDA and co-SDA employed in synthesis, as can be seen in Figure 1(1). This is in line with our hypothesis that the formation of the layered phases in this system is caused by the different fitting of the co-SDAs within the ferrierite cages, hindering the complete condensation of adjacent ferrierite sheets, as has been reported in ref. [27]. A particular case concerns the materials prepared with quinuclidine, that shows a shift of the (200) reflexion with the crystallisation time, which has been attributed to the exchange of the organic SDAs as the crystallisation proceeds, resulting in materials richer in bmp at short crystallisation times and in materials richer in quinuclidine for longer times of synthesis [27]. Indeed, ${ }^{29}$ Si MAS NMR shows the presence of a high amount of silanol groups (Q3 ) in this sample, evidencing the incomplete condensation of ferrierite layers [27]. Another evidence that suggests the presence of a high amount of uncondensed silanol groups in these samples is their high content of occluded organic material, which is between 15 wt $\%$ and $18 \mathrm{wt} \%$ (Table 2), depending on the sample. This amount is much higher than that of fully condensed ferrierite crystals discussed above (Fig.2 and Table 2), and this 
excess of organic material should be located at interlayer regions associated to Q3 silicon atoms. Indeed, it can be seen also in Table 2 that the TG weight loss at $\mathrm{T}>200$ ${ }^{\circ} \mathrm{C}$ is higher than the total organic content as determined by chemical analysis. This excess would correspond to the release of water coming from the condensation of silanol groups present in the solid. From this point of view, it is interesting to notice that the FER-bmprol-TMA samples possesses an organic content of ca. $13 \mathrm{wt} \%$, according to chemical analysis, which is lower than that of the other materials. Hence, this sample might constitute an intermediate case between the fully condensed ferrierite crystals and the highly uncondensed ferrierite-type materials.

After calcination, the samples show similar X-ray diffraction patterns as a result of the removal of the organic content between the layers and the partial condensation of the silanol groups of consecutive layers (Figure 1(2)). This is manifested by the shift of the (200) diffraction to higher $2 \theta$ values, particularly for the materials prepared with bmp and quinuclidine or TEA as co-SDAs. The solid synthesised with bmprol and TMA, does not seem to possess a layered structure similar to that of the samples crystallised with bmp and quinuclidine or TEA, since calcination of the material does not shift the lower-angle diffraction peak as much as in the former cases.

Scanning electron microscopy revealed a similar crystal size and morphology for the samples synthesised with bmp and different co-SDAs. These solids crystallised as aggregates of long needles of around 5-10 x 0.3-0.5 $\mu \mathrm{m}$ in size. The sample synthesised with bmprol shows a slightly different crystal shape and also possesses lower amount of amorphous material. The $\mathrm{Si} / \mathrm{Al}$ ratio of the samples (Table 1) is close to that of the nominal value of the gel $(\mathrm{Si} / \mathrm{Al}=15)$, although this ratio is slightly higher for the samples synthesised with TEA $(\mathrm{Si} / \mathrm{Al}=18.6)$. 
The textural properties of the calcined samples are summarised in Table 2. The higher BET areas correspond in general to the layered ferrierite materials, which could indicate that after calcination the layers are not completely condensed, in agreement with the IR results that will be discussed in the next section.

\section{FTIR characterisation of surface groups}

The O-H stretching region of the FTIR spectrum of sample FER-bmp-TMA outgassed at $400^{\circ} \mathrm{C}$ is shown in Figure 3 (a). The spectrum is similar to those of the other fully condensed ferrierite samples obtained in fluoride medium that have been reported elsewhere [21], and exhibits an intense asymmetric band at ca. $3601 \mathrm{~cm}^{-1}$ with a weak shoulder at $3550 \mathrm{~cm}^{-1}$, characteristic of bridging hydroxyl groups ( $\left.\mathrm{Si}-\mathrm{OH}-\mathrm{Al}\right)$, and a weaker band at $3747 \mathrm{~cm}^{-1}$, corresponding to terminal silanols. Upon contact with pyridine at $150{ }^{\circ} \mathrm{C}$ for $90 \mathrm{~min}$ (and subsequent removal of physically adsorbed pyridine in vacuum at $150{ }^{\circ} \mathrm{C}$ for $30 \mathrm{~min}$ ), it is observed a decrease of the intensity of both the terminal silanol and the bridging hydroxyl bands. Concomitantly, several bands corresponding to pyridine ring vibration modes appear in the $1700-1400 \mathrm{~cm}^{-1}$ range (Figure 3, right). The strong bands at 1545 and $1638 \mathrm{~cm}^{-1}$ are assigned to pyridinium cations, the weak band at $1455 \mathrm{~cm}^{-1}$, to pyridine interacting with Lewis sites, and the weak bands observed at 1445 and $1596 \mathrm{~cm}^{-1}$ are assigned to pyridine hydrogen-bonded to silanol groups [31, 32]. Furthermore, bands at $1620 \mathrm{~cm}^{-1}$ and $1490 \mathrm{~cm}^{-1}$ are observed, to which pyridine species interacting with both Brönsted and Lewis sites contribute. It can be observed in Figure 3 that the formation of pyridinium ions produces only a partial removal of the bridging hydroxyl band $\left(3601 \mathrm{~cm}^{-1}\right)$. It has been previously reported [21] that prolonging pyridine contact at $150{ }^{\circ} \mathrm{C}$ slightly decreased the intensity of the bridging hydroxyl band, although the band still retained a large fraction of its 
original intensity after contact with pyridine for $4 \mathrm{~h}$. It was concluded that only a part of the strong Brönsted acid sites are accessible to pyridine at $150{ }^{\circ} \mathrm{C}$ in all the fully condensed ferrierite samples, and that accessibility was dependent on the combination of organic molecules used as SDAs. Table 3 collects the estimated fraction of strong Brönsted sites accessible to pyridine for these samples and the relative concentration of Brönsted and Lewis sites probed by pyridine (expressed as normalised area of the corresponding IR bands). The samples show noticeable differences in Brönsted sites accessibility, although some disagreement is observed between this parameter and the concentration of pyridinium ions, which suggests differences in the total concentration of Brönsted sites among the samples. The weak intensity of the band at $1455 \mathrm{~cm}^{-1}$ shows that these samples possess a low content of extra-framework aluminium, being samples FER-bmp-TMA and FER1 those exhibiting the highest intensity for this band. The FTIR spectra of the poorly condensed samples synthesised in fluoride medium, outgassed at $400{ }^{\circ} \mathrm{C}$ show marked differences with respect to the spectra of the fully condensed ones. For the samples obtained substituting TMA by TEA or quinuclidine as co-SDA in the syntheses with bmp (Figure 3, c-e), the terminal silanol band exhibits higher intensity, in agreement with the expected higher concentration of silanols in these samples. This band shows a marked broadening which can be attributed to extensive hydrogen-bonding between neighbouring silanol groups, probably due to close proximity between silanol groups in two adjacent non-fully condensed ferrierite layers. Furthermore, the spectra show broad shoulders at ca. 3700 and $3650 \mathrm{~cm}^{-1}$, that might be derived from Lewis extra-framework species [8, 11]. All these features suggest the presence of a large number of condensation defects in these samples. Furthermore, these samples exhibit much lower intensity (up to one order of magnitude lower) for the band corresponding to bridging Si-OH-Al groups. However, pyridine adsorption shows 
that the concentration of Brönsted acid sites able to protonate pyridine is similar for all the samples synthesised with bmp and different co-SDAs (Table 3). After pyridine adsorption at $150{ }^{\circ} \mathrm{C}$ for $5 \mathrm{~min}$, the band at $3600 \mathrm{~cm}^{-1}$ was partly removed, its intensity was hardly decreased after contact with pyridine for $30 \mathrm{~min}$, and remained constant at longer contact time (Figure 3, c-e, left). Despite the much lower intensity of the bridging hydroxyl band, and that only part of these sites are accessible to pyridine, the integrated area of the band due to pyridinium species is comparable to that of FERbmp-TMA. This result suggests that only those Si-OH-Al species located in fully connected crystalline environments of ferrierite would give rise to the band around 3600 $\mathrm{cm}^{-1}$. On the other hand, non-fully connected zeolite units would allow for a large variety of T-O-T angles and, hence, the Si-OH-Al species associated to these sites would not exhibit a well-defined vibration frequency of the hydroxyl group. A further evidence that supports this conclusion is given by the changes observed in the FTIR spectra of samples FER-bmp-quin at different crystallisation times. Increasing the duration of the hydrothermal treatment from 10 to 30 days is known to lead to a higher degree of condensation of the ferrierite layers [27], and this change is accompanied by a decrease of the intensity of the silanol band and an increase of the bridging hydroxyl band. It is worth to note also that the pyridinium band $\left(1545 \mathrm{~cm}^{-1}\right)$ is significantly broader for samples FER-bmp-TEA and FER-bmp-quin as compared to FER-bmpTMA, which also suggests a higher heterogeneity of the Brönsted acid sites of the former samples. According to the previous interpretation of the FTIR results, accessibility of pyridine to the Brönsted sites could not be directly related to the decrease of intensity of the band at $3600 \mathrm{~cm}^{-1}$ in the case of partly condensed ferrieritetype samples. Pyridine adsorption also shows a markedly higher concentration of Lewis sites for samples FER-bmp-TEA and FER-bmp-quin (Table 3). Finally, it can be 
observed in Figure 3 that, for these samples, there is a progressive increase of the intensity of bands assigned to hydrogen-bonded pyridine, with a concomitant decrease of the silanol bands, with increasing time of pyridine adsorption. This result suggests that access of pyridine to the silanol groups is constrained, revealing a high tortuosity of the interlayer spacings created by partial condensation of the ferrierite sheets. It can also be observed that prolonged contact with pyridine also leads to an increase of the shoulder at $3650 \mathrm{~cm}^{-1}$ attributed to Al-OH species [33-35], mainly for samples FERbmp-TEA and FER-bmprol-TMA, which origin is not clear at present.

The results of the FTIR characterisation discussed above support the conclusion that substitution of TMA by bulkier co-SDAs (TEA and quinuclidine) in the syntheses using bmp as SDA, lead to materials that retain a large number of condensation defects after calcination. In contrast, replacement of bmp by bmprol while keeping TMA as co-SDA seems to produce much less noticeable changes in the condensation degree of the calcined samples, in agreement with results shown above. The spectrum of pretreated sample FER-bmprol-TMA is similar to that of FER-bmp-TMA, showing a slightly more intense silanol band of similar width, and a slightly less intense $\mathrm{Si}-\mathrm{OH}-\mathrm{Al}$ band (Figure 3). The concentration of Lewis sites determined by pyridine adsorption is also close between these two samples. On the other hand, the amount of Brönsted acid sites accessible to pyridine in sample FER-bmprol-TMA seems to be nearly twice the amount in FER-bmp-TMA, based on the intensity of the pyridinium band (Table 3).

It can be concluded that, after calcination, samples synthesised using pyrrolidine in alkaline medium and, either alone or with TMA as co-SDA, in fluoride medium can be considered as ferrierite samples with low number of defects. Zeolites synthesised with TMA and either bmp or bmprol would belong also to this group, although the samples seem to possess an increased number of defects in the following order: FER-pyrr-TMA 
$<$ FER-bmp-TMA $<$ FER-bmprol-TMA. On the other hand, replacement of TMA by the bulkier co-SDAs TEA and quinuclidine in the syntheses carried out with bmp leads to samples with a high content of condensation defects.

\section{Catalytic activity}

\section{Low-defect samples}

Tables 4 and 5 collect reaction conversion expressed as that of all n-butene isomers, 1-, 2- trans and 2-cis, for double bond shift and cis-trans isomerisation of n-butenes reach the equilibrium and they are much faster than skeletal isomerisation. Selectivity to the different reaction products of several catalysts for two different time-on-stream (t.o.s.), 5 and 720 minutes is also reported. The dependence of n-butene conversion, selectivity and isobutene yield on t.o.s. are depicted in Figures 4 and 5 for low- and high-defect samples, respectively. Nonetheless, data corresponding to the low-defect sample FERbmprol-TMA have been plotted in Fig. 5 for comparison purposes.

Several features can be observed in Tables 4 and 5. First, at t.o.s. of 5 minutes, the conventional catalyst (FER1) presents the highest conversion, but the lowest isobutene selectivity. For all the catalysts, the yields of the two other major products, $\mathrm{C}^{=}$and $\mathrm{C}^{5}$, are quite close to each other, which evidences that they are formed via butene dimerisation-cracking.

A yield to $\mathrm{C} 6$ higher than that to $\mathrm{C} 7$ is obtained for the conventional catalyst, opposite to what is obtained for the catalysts synthesised in fluoride medium. Finally, minor amount of n- and i-butane are formed, followed in decreasing order by ethylene, propane and $\mathrm{C} 5$.

For all catalysts, the conversion decreases as a function of t.o.s. (Figure 4) but marked differences in the deactivation pattern are observed among them, depending upon the 
synthesis method of the ferrierite crystals. For the conventional catalyst, an activity loss of $70 \%$ is obtained after 720 minutes of t.o.s., while the selectivity to isobutene increases from $24 \%$ to only $38 \%$, and the dimerisation/oligomerisation of butene followed by cracking still contribute notoriously to the overall butene conversion. In contrast to this behaviour, the samples obtained with TMA-bmp or TMA-bmprol (Table 4) not only posses a higher initial selectivity to isobutene (t.o.s. $=5$ minutes), but also deactivate at lower rate (Figs. 4 and 5). Indeed, while the yield to isobutene only decreases slightly after $13 \mathrm{~h}$ of run, the butene oligomerisation is suppressed in more than $90 \%$ in that period of time, which results in a selectivity to isobutene higher than $90 \%$. Then, the selective deactivation of the oligomerisation/cracking pathway with t.o.s. is the main contributor to the activity decay. It is particularly noticeable the behaviour of the sample synthesised from TMA and bmp at long crystallisation time (83 days), which exhibits the highest isobutene yield, and presents the lowest deactivation rate (Figure 4).

Samples synthesised in fluoride medium from gels containing pyrrolidine are much less active, and, although the highly deactivated samples present a good selectivity to isobutene, this decreases very rapidly with the conversion (Figure 4), and therefore a very low isobutene yield is obtained at high t.o.s.

These results evidence that the main pathway for isobutene formation on these catalysts is the monomolecular skeletal isomerisation of n-butene. In order to explain these results, it has to be considered first that only a fraction of acid sites are interacting with adsorbed pyridine, as it is shown in Table 3, and those sites should be located in the 10MR channel and would be engaged in n-butene activation $[18,36]$. As it has been discussed elsewhere [21], the location of Al sites in the framework is a function of the particular combination of co-structure directing agents incorporated into the crystals. 
The presence of TMA and pyrrolidine in the ferrierite cage is directing the Al sitting toward this cage, which give rise to the formation of acid sites non available to interact with the n-butene molecule. This effect of "pumping" aluminium into cage sites has as a consequence that less aluminium would be available to occupy accessible 10-MR channel sites, which strongly reduces the acid site density in those channels. Therefore, the actual $\mathrm{Si} / \mathrm{Al}$ ratio in the channels must be much lower than the average $\mathrm{Si} / \mathrm{Al}$ ratio of the whole crystals. This decrease in acid sites density at the channels should greatly decrease the catalyst ability to promote non-selective bimolecular dimerisation/oligomerisation reactions.

The beneficial effect of lowering the number of acid sites of ferrierite on isobutene selectivity has been reported by several research teams [17, 37], which has also been extended to MCM-22 catalysts [38]. However, these procedures require either the synthesis of ferrierite crystals with a very high $\mathrm{Si} / \mathrm{Al}$ ratio, which has a detrimental impact on catalyst activity, or dealumination procedures that require additional steps to remove extra-framework aluminium species [17] that otherwise would produce a deleterious effect on both activity and selectivity.

In spite of acid sites location and density, some other effects might contribute to the observed overall catalytic pattern. For the two samples synthesised from pyrrolidinecontaining gels in fluoride medium, their large crystal size could eventually contribute to faster catalyst deactivation, due to severe pore blocking of the channels by coke deposits. However, it has also to be considered that ferrierite catalysts with ca. 20 microns crystal size $(\mathrm{Si} / \mathrm{Al}=14.4)$ prepared from 1,4-diaminobutane in the absence of inorganic cations have been reported to show n-butene conversion higher than that of ferrierite with small crystal size and they are also more selective to $\mathrm{C} 3^{=}$and $\mathrm{C} 5^{-}[12]$. Moreover, these authors argued that the remarkable isobutene selectivity of aged $\mathrm{H}$ - 
ferrierite could be correlated with the density of the Brönsted acid sites located near the 10-ring pore mouth, which is in agreement with the effect reported here on the influence of SDA on Al location.

It is also to notice the remarkable increase of isobutene yield obtained by increasing the crystallisation time in the TMA/bmp gel from 20 to 83 days. It can be observed in Table 2 that the amount of organic material occluded inside the crystals decreases with crystallisation time, and hence the catalyst would have less concentration of silanol defect groups. From this observation, it could be eventually concluded that the presence of such defects might be detrimental for catalysts selectivity to isobutene. This aspect has been further explored in more detail in the samples that contain a very high amount of silanol groups, as described below.

\section{High-defect samples}

Another factor influencing catalyst performance to which attention has been paid concerns the presence of Lewis sites and connectivity defects, i.e., silanol groups. The ferrierite samples described so far contain very little extra-framework aluminium, and a low amount of $\mathrm{SiOH}$ groups, which is not surprising owing to the fact the synthesis has been performed in fluoride medium [39]. However, the materials synthesised from a combination of bmp with either quinuclidine or TEA shows a much higher concentration of silanol groups as well as Lewis sites, as it has been discussed in previous section, and this produces noticeable changes in the pattern of catalytic nbutene transformation. Table 5 collects the activity and products selectivity of several high-defect samples for t.o.s. of 5 and 720 minutes, while the dependence of n-butene conversion, selectivity and isobutene yield on t.o.s. is depicted in Figure 5. The most noticeable difference with respect to the samples having low-defect concentration is the 
fast decay of catalyst activity of the high-defect ferrierite catalysts. After $12 \mathrm{~h}$ of run, the residual activity is between $15 \%$ and $25 \%$ that of t.o.s. $=5$ minutes, depending on the type of catalyst. It is also noteworthy that, for the samples synthesised from quinuclidine-containing gels, the sample obtained at longer crystallisation time is more resistant toward deactivation, and, as it was discussed above, it indeed contains less amount of defects. For all these high-defect samples, the selectivity to isobutene is always below $80 \%$, and poor yields to this product are obtained at high t.o.s., which are lower than $5 \%$ already after $12 \mathrm{~h}$ of reaction.

Although the presence of a high amount of silanol groups correlates with both high activity decay rate and low isobutene selectivity, it has to be taken into account that, as it was discussed in the previous section, an intense pyridine band associated to Lewis sites is also observed for these catalysts, its intensity increasing with that of the band attributed to silanol groups. It has been reported elsewhere that the simultaneous presence of Lewis and Brönsted sites in ferrierite catalysts enhances di-, oligomerisation/cracking reactions, leading to higher yields of by-products [18]. We are observing the same trend towards increasing by-products formation as far as the presence of Lewis sites proven by pyridine adsorption is concerned, but the detection of the two Lewis bands, and the simultaneous detection of high amount of defects silanol groups, preclude, in our opinion, a clear conclusion on the individual contribution of both chemical species to catalysts performance, i.e., extra-framework species coming from framework dealumination and silanol groups.

It is also interesting to observe that there seems to be a threshold value of defect content (contributed by extra-framework aluminum and silanol chemical species) in regard to the influence of this parameter on catalysts performance. Indeed, the sample FERbmprol-TMA contains an intermediate amount of silanol groups and Lewis sites, which 
is higher than that present in the samples synthesised from either bmp of pyrrolidinecontaining gels. However, the isobutene yield (Table 5) is even higher than that obtained from the latter, whereas it is also more resistant toward deactivation (Figure 5).

\section{CONCLUSIONS}

The activity in the transformation of n-butenes and selectivity to isobutene of ferrierite catalysts can be greatly improved by synthesising the zeolite crystals in the presence of appropriate combination of structure directing agents in the absence of alkaline cations. These specific combinations of SDA allow to exert an effective control on the density of acid sites located at the 10-MR channel, where the reaction takes place. For SDA too bulky to be occluded in the ferrierite cage, a high amount of both silanol defects and Lewis acid sites are found in the resulting catalysts. The presence of such type of sites enhances the formation of by-products and promotes in a great extension catalysts deactivation.

\section{Acknowledgements}

We are thankful for the financial support of the Spanish Ministry of Science and Innovation (MICINN, former MEC), project CTQ2006-06282. A.B.P. acknowledges the Spanish MICINN for a predoctoral grant. R.G. acknowledges the J.A.E. contract (CSIC). 


\section{REFERENCES}

1: P. Grandvallet, K. P. de Jong, H. H. Mooiweer, A. G. T. G. Kortbeek, B. KraushaarCzarnetzki, European Patent EP501577 (1992).

2: H. H. Mooiweer, K. P. de Jong, B. Kraushaar-Czarnetzki, W. H. J. Stork, S. C. Krutzen, Stud. Surf. Sci. Catal. 84 (1994) 2327.

3: J. Houzvicka, V. Ponec, Catal. Rev. Sci. Eng. 39(4) (1997) 319.

4: W.-Q. Xu, Y. -G. Yin, S. L. Suib, C.-L. O’ Young, J. Phys. Chem. 99 (1995) 758.

5: P. Meriaudeau, R. Bacaud, L. N. Hung, T. A. Vu, J. Mol. Catal. A 110 (1996) L 177.

6: K. P. de Jong, H. H. Mooiweer, J. G. Buglass, P. K. Maarsen, Stud. Surf. Sci. Catal. 111 (1997) 127.

7: J. Čejka, B. Wichterlová, P. Sarv, Appl. Catal. A 179 (1999) 217.

8: B. de Ménorval, P. Ayrault, N. S. Gnep, M. Guisnet, J. Catal. 230 (2005) 38.

9 : M. Kangas, J. Villegas, N. Kumar, T. Salmi, D. Yu. Murzin, F. Sandelin, E. Harlin, Catal. Today, $100(2005) 363$.

10: M. Guisnet, P. Andy, N.S. Gnep, C. Travers, E. Benazzi, Stud. Surf. Sci. Catal. 105 (1997) 1365.

11: S. van Donk, E. Bus, A. Broersma, J.H. Bitter, K.P. de Jong, Appl. Catal. A 237, (2002) 149.

12: S.-H. Lee, C.-H. Shin, S.B. Hong, J. Catal., 223 (2004) 200.

13: J.A.Z. Pieterse, S. Veefkind-Reyes, K. Seshan, L. Domokos, J.A. Lercher, J. Catal. 187 (1999) 518.

14: A. Martucci, A. Alberti, G. Cruciani, P. Radaelli, P. Ciambelli, M. Rapacciulo, Microporous Mesoporous Mater. 30 (1999) 95.

15: V.L. Zholobenko, D.B. Lukyanov, J. Dwyer, W.J. Smith, J. Phys. Chem. B 102 (1998) 2715. 
16: B. Wichterlová, Z. Tvarůžková, Z. Sobalík, P. Sarv, Microporous Mesoporous Mater. 24 (1998) 223.

17: W.-Q. Xu, Y. -G. Yin, S. L. Suib, J. C. Edwards, C.-L. O’Young, J. Catal., 163 (1996) 232.

18: B. Wichterlová, N. Žilkova, E. Uvarova, J. Čejka, P. Sarv, C. Paganini, J.A. Lercher, Appl. Catal. A 182 (1999) 297.

19: G. Onyestyák, Microporous Mesoporous Mater. 104 (2007) 192.

20: K. Frolich, R. Bulánek, P. Nachtigall, Proceedings of the 40th Symposium on Catalysis, Prague, 2008, p. 40.

21: A.B. Pinar, C. Márquez-Álvarez, M. Grande-Casas, J. Pérez-Pariente, manuscript submitted to J. Catal.

22: A.B. Pinar, J. Pérez-Pariente, L. Gómez-Hortigüela, world patent WO 2008/116958.

23: L. Schereyeck, P. Caullet, J. C. Mougenel, J. L. Guth, B. Marler, Microporous Mater. 6 (1996) 259.

24: A. Burton, R. J. Accardi, R. F. Lobo, M. Falcioni, M.W. Deem, Chem. Mater. 12 (2000) 2936.

25: R. Millini, L. C. Carluccio, A. Carati, G. Bellussi, C. Perego, G. Cruciani, S. Zanardi, Microporous Mesoporous Mater. 74 (2004) 59.

26: L.M. Knight, M.A. Miller, S.C. Koster, M.G. Gatter, A.I. Benin, R.R. Willis, G.J. Lewis, R.W. Broach, Stud. Surf. Sci. Catal. 170 (A) (2007) 338.

27: R. García, L. Gómez-Hortigüela, I. Díaz, E. Sastre, J. Pérez-Pariente, Chem. Mater. $20(2008) 1099$.

28: R.Garcia, A.B. Pinar, C. Márquez-Álvarez, E.Sastre, J.Pérez-Pariente, Collect. Czech. Chem. Commun. 73 (2008) 1089.

29: C.J. Plank, E.J. Rosinski, M.K. Rubin, US Patent 4016245 (1977). 
30: A.B. Pinar, L. Gómez-Hortigüela, J. Pérez-Pariente, Chem. Mater. 19 (2007) 5617.

31: E.P. Parry, J. Catal. 2 (1963) 371.

32: T.R. Hughes, H.M. White, J. Phys. Chem. 71 (1967) 2192.

33: Y.S. Jin, A. Auroux, J.C. Vedrine, Appl. Catal. 37 (1988) 1

34: M. Trombetta, G. Busca, S. Rossini, V. Piccoli, U. Cornaro, A. Guercio, R. Catani, R.J. Willey, J. Catal. 179 (1998) 581.

35: V.L. Zholobenko, E.R. House, Catal. Lett. 89 (2003) 35.

36: L. Domokos, L. Lefferts, K. Seshan, J.A. Lercher, J. Mol. Catal. A 162 (2000) 147.

37: M.A. Asensi, A. Martínez, Appl. Catal. A 183 (1999) 155.

38: M. A. Asensi, A. Corma, A. Martínez, J. Catal. 158 (1996) 561.

39: L. A. Villaescusa, M. A. Camblor, Recent Res. Dev. Chem., 1 (2003) 93. 


\section{FIGURE CAPTIONS}

Figure 1. XRD patterns of selected (1) as-prepared and (2) calcined samples: a) FERbmp-quin-10d, b) FER-bmp-TEA-11d, c) FER-bmp-quin-30d, d) FER-bmprol-TMA20d, e) FER-pyrr-10d.

Figure 2. Thermogravimetric analysis of as-synthesised samples a) FER-bmp-quin-10d, b) FER-bmprol-TMA-20d, c) FER-pyrr-10d.

Figure 3. FTIR spectra in the $v_{\mathrm{OH}}$ region (left) and difference spectra in the pyridine ring vibrations region (right) of calcined samples FER-bmp-TMA-20d (a), FER-bmprolTMA-20d (b), FER-bmp-TEA-11d (c), FER-bmp-quin-10d (d) and FER-bmp-quin-30d (e). The spectra of the samples outgassed at $400^{\circ} \mathrm{C}$ are shown in full thick line. Spectra recorded after pyridine adsorption at $150^{\circ} \mathrm{C}$ for increasing periods of time are shown in dotted line (5 and $30 \mathrm{~min}$ ) and full thin line (90 $\mathrm{min})$.

Figure 4. Conversion (a), selectivity to isobutene (b), isobutene yield (c) and selectivity to isobutene as a function of the conversion (d) for the low-defect samples.

Figure 5. Conversion (a), selectivity to isobutene (b), isobutene yield (c) and selectivity to isobutene as a function of the conversion (d) for the high-defect samples. The lowdefect sample FER-bmprol-TMA sample is included for comparison purposes. 


\section{FIGURES}

Figure 1.
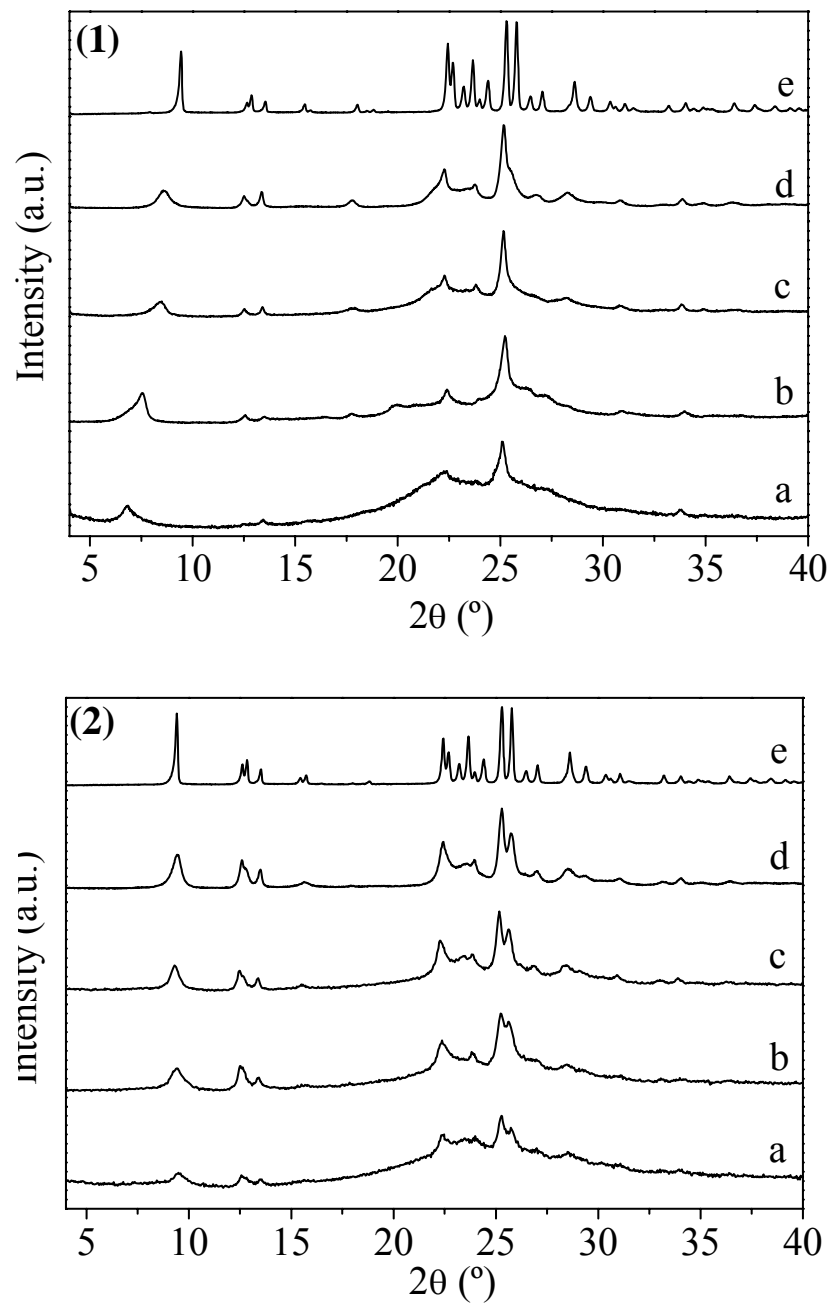
Figure 2.

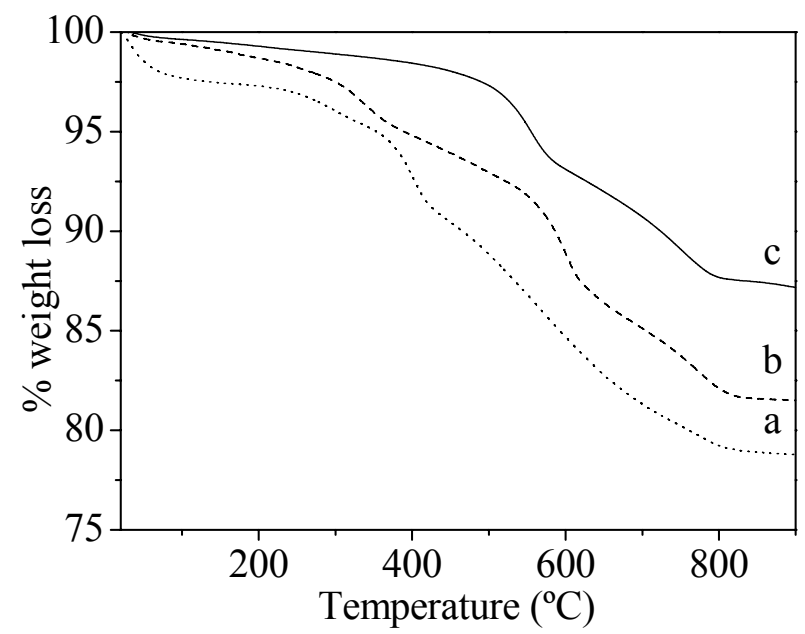


Figure 3.
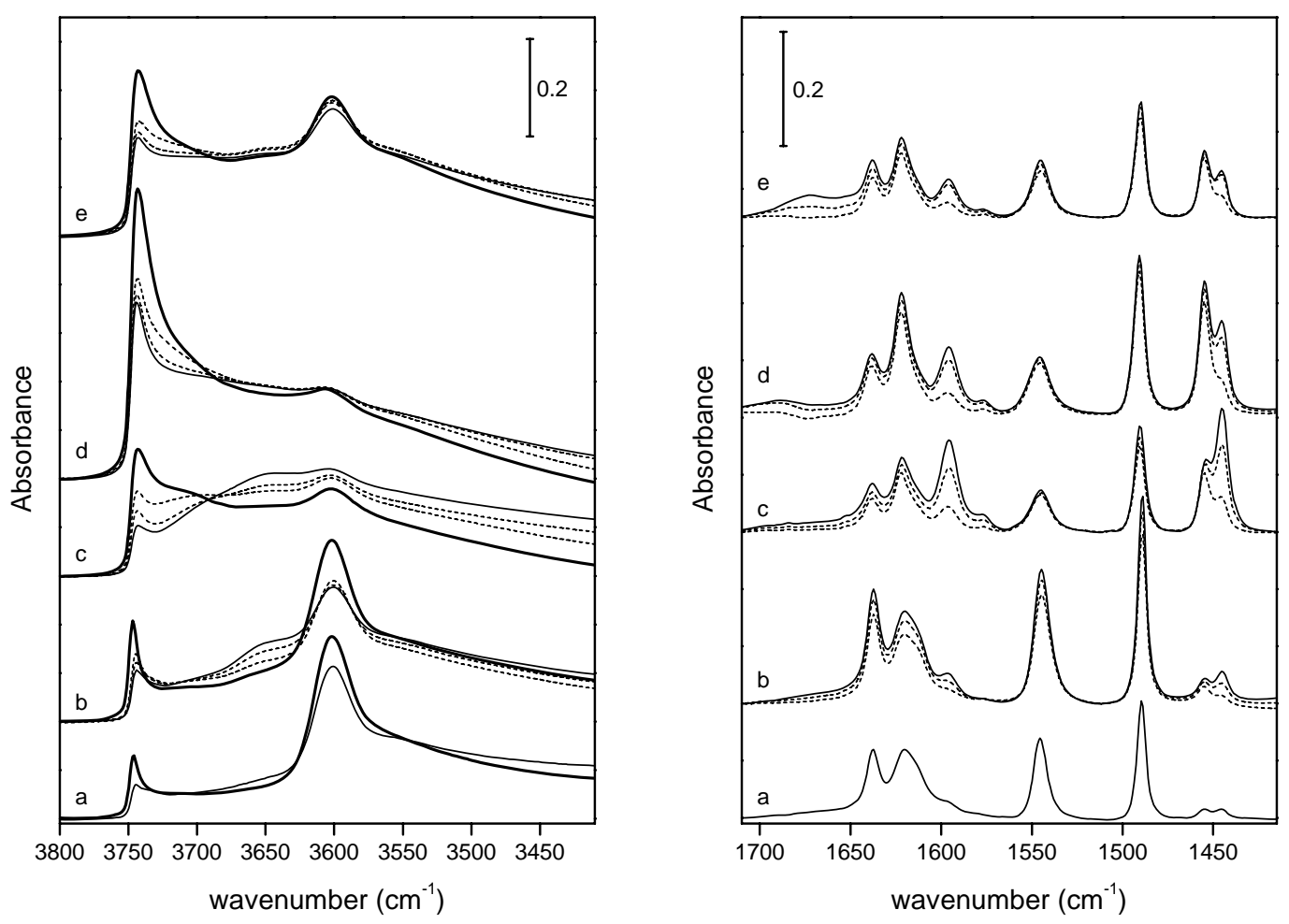
Figure 4.
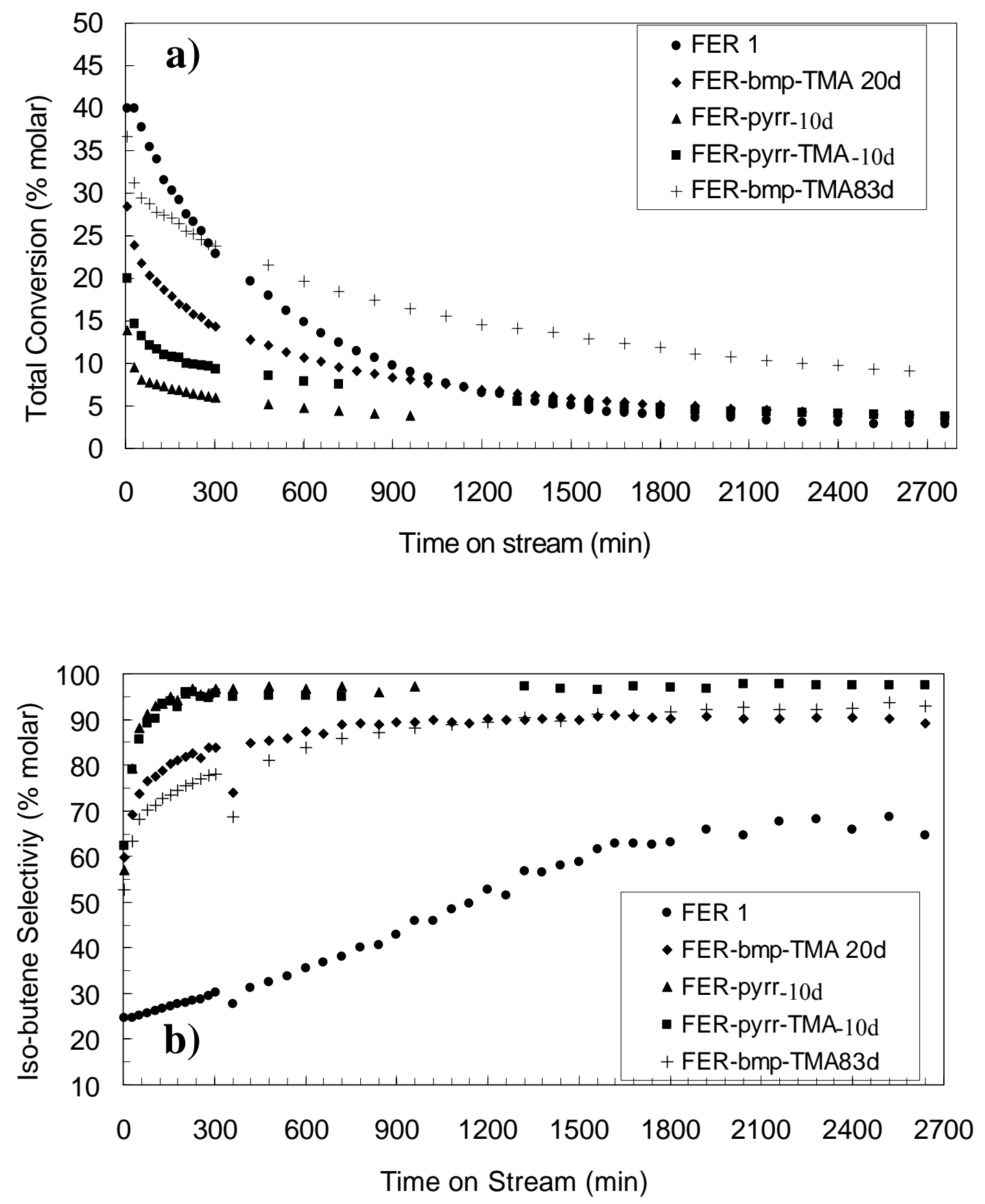

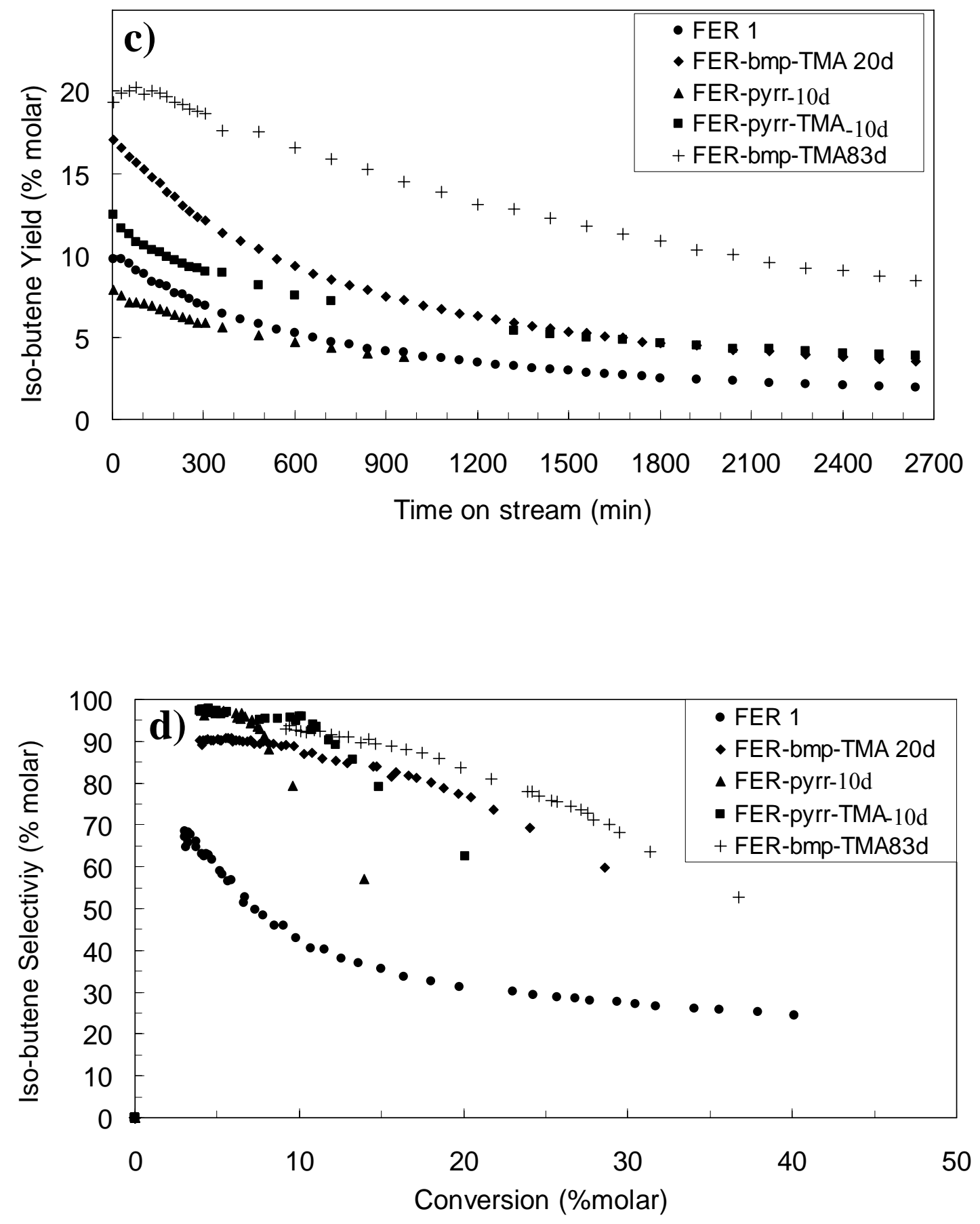
Figure 5.
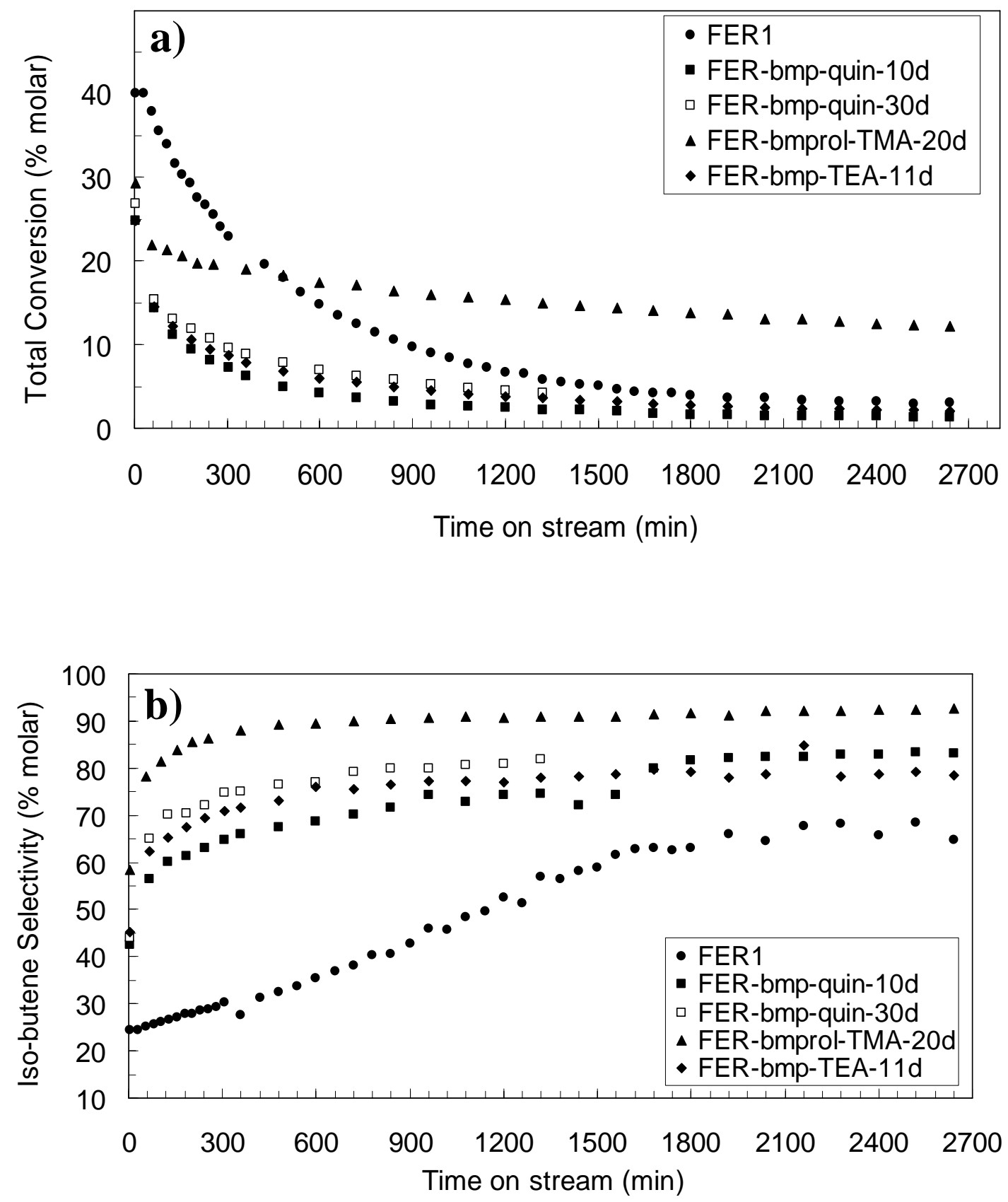

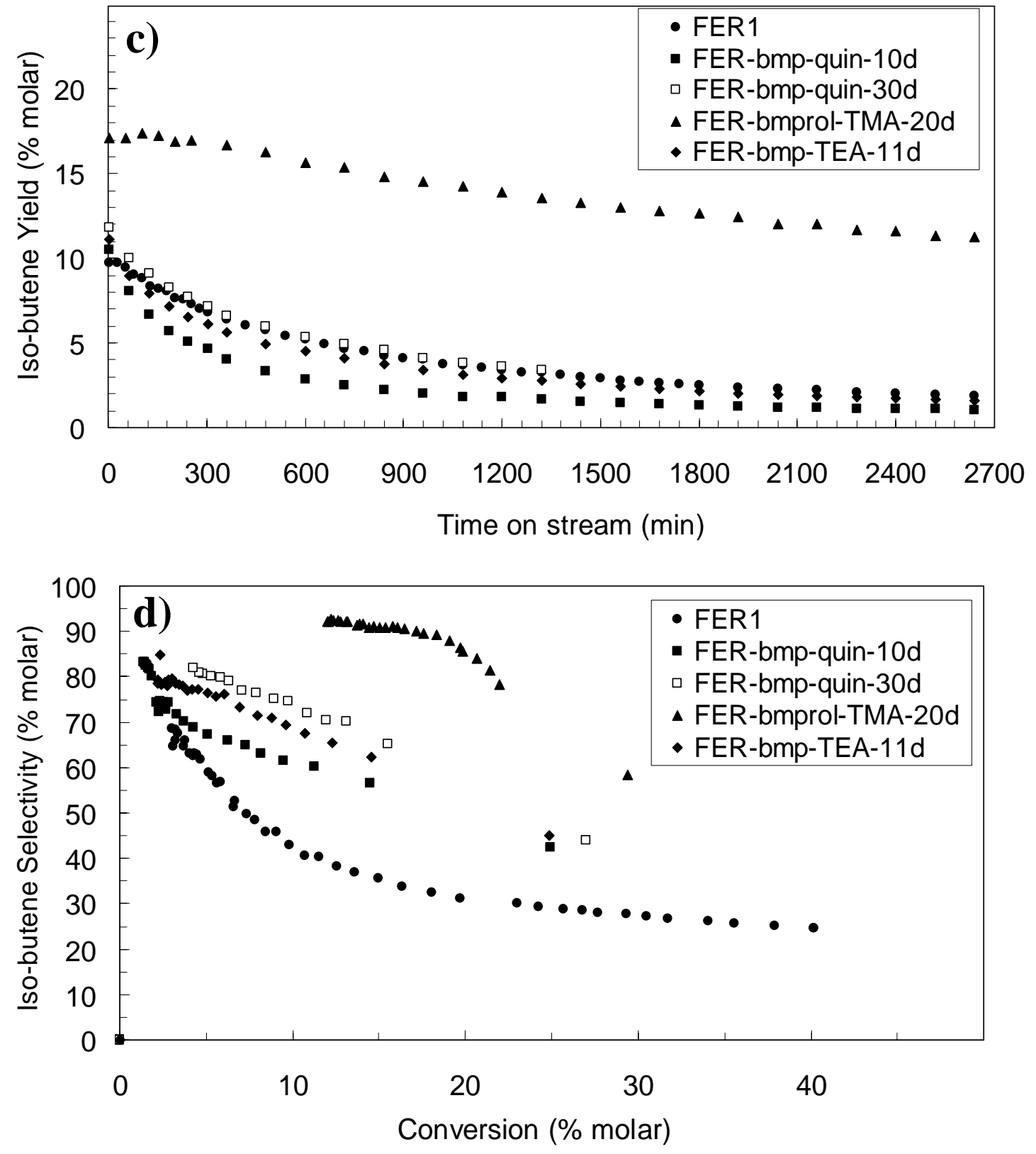


\section{TABLES}

Table 1. Summary of the syntheses carried out with the different combinations of SDAs and $\mathrm{Si} / \mathrm{Al}$ ratio of the solid products obtained. The gels compositions were: 0.06 coSDA: $0.48 \mathrm{ROH}: 0.48 \mathrm{HF}: 0.03 \mathrm{Al}_{2} \mathrm{O}_{3}: 0.94 \mathrm{SiO}_{2}: 4.3-4.7 \mathrm{H}_{2} \mathrm{O}$, heated at $135^{\circ} \mathrm{C}$. The ferrierite-type samples were heated at $150{ }^{\circ} \mathrm{C}$ (except FER1 sample, heated at $175{ }^{\circ} \mathrm{C}$ ) and the fully-condensed samples were heated at $135^{\circ} \mathrm{C}$.

\begin{tabular}{lccccl}
\hline Sample & ROH & co-SDA & t (days) & Si/Al(EDX) & Product \\
& \multicolumn{7}{c}{ Ferrierite-type materials } \\
FER-bmp-quin-10d & bmp & quin & 10 & $14.6^{\mathrm{a}}$ & FER-related \\
FER-bmp-quin-30d & bmp & quin & 30 & $15.5^{\mathrm{a}}$ & FER-related \\
FER-bmp-TEA-11d & bmp & TEA & 11 & 18.6 & FER-related \\
FER-bmprol-TMA-20d & bmprol & TMA & 20 & 15.8 & FER-related \\
\hline & Fully-condensed ferrierite & & \\
FER-bmp-TMA-20d & bmp & TMA & 20 & 15.5 & Ferrierite \\
FER-bmp-TMA-83d & bmp & TMA & 83 & 15.6 & Ferrierite \\
FER-pyrr-TMA-10d & pyrr & TMA & 10 & 15.9 & Ferrierite \\
FER-pyrr-10d & pyrr & - & 10 & 15.0 & Ferrierite \\
FER1 & pyrr & - & 14 & 15.8 & Ferrierite \\
\hline
\end{tabular}

a: ICP analysis 
Table 2. Organic content and thermogravimetric analysis data of as-synthesised samples, and BET surface area of calcined materials.

\begin{tabular}{|c|c|c|c|c|c|}
\hline \multirow[b]{3}{*}{ Sample } & \multicolumn{4}{|c|}{ Chemical analysis } & \multirow[b]{3}{*}{$\mathrm{S}_{\mathrm{BET}}\left(\mathrm{m}^{2} / \mathrm{g}\right)$} \\
\hline & \multicolumn{3}{|c|}{ (wt.\%) } & \multirow{2}{*}{$\begin{array}{c}\text { TGA }^{\mathrm{a}} \\
\text { wt.\% }\end{array}$} & \\
\hline & $\mathrm{C}$ & $\mathrm{H}$ & $\mathrm{N}$ & & \\
\hline \multicolumn{6}{|c|}{ Ferrierite-type materials } \\
\hline FER-bmprol-TMA-20d & 9.38 & 2.05 & 1.73 & 17.1 & 261 \\
\hline FER-bmp-TEA-11d & 13.87 & 2.68 & 1.75 & 20.9 & 285 \\
\hline FER-bmp-quin-10d & 12.51 & 2.32 & 1.55 & 18.5 & 446 \\
\hline FER-bmp-quin-30d & 11.75 & 2.20 & 1.75 & 17.9 & 374 \\
\hline \multicolumn{6}{|c|}{ Fully-condensed ferrierite } \\
\hline FER-bmp-TMA-20d & 9.30 & 1.83 & 1.73 & 13.7 & 305 \\
\hline FER-bmp-TMA-83d & 8.40 & 1.66 & 1.62 & 11.7 & - \\
\hline FER-pyrr-TMA-10d & 7.58 & 1.86 & 1.97 & 11.6 & 341 \\
\hline FER-pyrr-10d & 7.35 & 1.74 & 2.00 & 11.2 & 350 \\
\hline FER1 & 5.48 & 1.38 & 1.61 & 9.6 & 244 \\
\hline
\end{tabular}

${ }^{\text {a }}$ Weight loss in the range $200-900{ }^{\circ} \mathrm{C}$ as measured by thermogravimetric analysis, associated to the decomposition/combustion of organic material and removal of silanol groups as water. 
Table 3. FTIR characterisation of acid sites ${ }^{a}$

\begin{tabular}{lccc}
\hline \multicolumn{1}{c}{ Sample } & $\begin{array}{c}\text { Brönsted sites } \\
\text { accessibility }^{\mathrm{b}}(\%)\end{array}$ & $\begin{array}{c}\text { Py-B band area } \\
\left(\mathrm{cm}^{-1}\right)\end{array}$ & $\begin{array}{c}\text { Py-L band area } \\
\text { d }\end{array}$ \\
\hline FER1 & 52 & 1.74 & 0.12 \\
FER-pyrr-10d & 10 & 0.95 & 0.05 \\
FER-pyrr-TMA-10d & 18 & 1.59 & 0.05 \\
FER-bmp-TMA-20d & 36 & 1.31 & 0.12 \\
FER-bmprol-TMA-20d & & 2.48 & 0.48 \\
FER-bmp-TEA-11d & & 1.13 & 1.86 \\
FER-bmp-quin-10d & & 1.50 & 1.57 \\
FER-bmp-quin-30d & & 1.31 & 0.80 \\
\hline
\end{tabular}

${ }^{a}$ Data obtained by adsorption of pyridine at $150^{\circ} \mathrm{C}$ for $90 \mathrm{~min}$

${ }^{b}$ Decrease of intensity of the bridging hydroxyl band at $3601 \mathrm{~cm}^{-1}$

${ }^{\mathrm{c}}$ Area of the pyridinium band $\left(1545 \mathrm{~cm}^{-1}\right)$

${ }^{\mathrm{d}}$ Area of the pyridine coordinated to Lewis sites $\left(1455 \mathrm{~cm}^{-1}\right)$ 
Table 4. Catalytic activity in the n-butene isomerisation for the low-defect samples.

\begin{tabular}{|c|c|c|c|c|c|c|c|c|c|c|c|c|}
\hline \multirow{2}{*}{$\frac{\text { Samples }}{\text { Time (min.) }}$} & \multicolumn{2}{|c|}{ FER1 } & \multicolumn{2}{|c|}{ FER-bmp-TMA-20d } & \multicolumn{2}{|c|}{ FER-bmp-TMA-83d } & \multicolumn{2}{|c|}{ FER-bmprol-TMA-20d } & \multicolumn{2}{|c|}{ FER-pyrr-10d } & \multicolumn{2}{|c|}{ FER-pyrr-TMA-10d } \\
\hline & 5 & 720 & 5 & 720 & 5 & 720 & 5 & 720 & 5 & 720 & 5 & 720 \\
\hline $\begin{array}{c}\text { Conversion } \\
(\% \text { molar })\end{array}$ & 40.15 & 12.54 & 28.58 & 9.66 & 36.67 & 18.52 & 29.42 & 17.16 & 13.95 & 4.52 & 20.07 & 7.61 \\
\hline \multicolumn{13}{|c|}{ Selectivity (\% molar) } \\
\hline $\mathrm{C} 1$ & 0.00 & 0.00 & 0.00 & 0.00 & 0.00 & 0.00 & 0.00 & 0.00 & 0.13 & 0.00 & 0.10 & 0.00 \\
\hline $\mathrm{C} 2$ & 0.00 & 0.00 & 0.00 & 0.00 & 0.00 & 0.00 & 0.00 & 0.00 & 0.13 & 0.00 & 0.00 & 0.00 \\
\hline $\mathrm{C} 2^{=}$ & 0.83 & 0.18 & 1.09 & 0.00 & 1.16 & 0.00 & 1.13 & 0.00 & 2.83 & 0.00 & 2.11 & 0.00 \\
\hline $\mathrm{C} 3$ & 0.86 & 0.15 & 0.81 & 0.00 & 1.10 & 0.00 & 0.80 & 0.00 & 1.51 & 0.00 & 1.07 & 0.00 \\
\hline $\mathrm{C} 3^{=}$ & 27.45 & 21.16 & 16.61 & 1.56 & 17.28 & 2.02 & 14.71 & 1.79 & 22.97 & 0.62 & 19.36 & 0.61 \\
\hline $\mathrm{I}-\mathrm{C} 4$ & 1.10 & 0.73 & 0.73 & 0.37 & 2.09 & 0.30 & 1.02 & 0.28 & 0.35 & 0.67 & 0.38 & 0.40 \\
\hline $\mathrm{N}-\mathrm{C} 4$ & 1.67 & 1.26 & 4.27 & 0.78 & 3.94 & 0.68 & 3.58 & 0.70 & 4.21 & 0.79 & 3.69 & 0.59 \\
\hline $\mathrm{I}-\mathrm{C} 4=$ & 24.55 & 38.16 & 59.88 & 88.88 & 52.77 & 85.92 & 58.46 & 89.99 & 57.05 & 97.28 & 62.43 & 95.00 \\
\hline C5 & 1.58 & 0.31 & 0.18 & 0.00 & 0.55 & 0.00 & 0.17 & 0.00 & 0.24 & 0.00 & 0.19 & 0.00 \\
\hline $\mathrm{C} 5^{=}$ & 26.07 & 23.37 & 12.94 & 2.00 & 16.04 & 2.79 & 10.77 & 2.07 & 9.06 & 0.64 & 9.02 & 0.63 \\
\hline C6 & 13.08 & 6.86 & 2.49 & 0.00 & 3.65 & 0.00 & 2.25 & 0.00 & 1.40 & 0.00 & 1.34 & 2.77 \\
\hline $\mathrm{C} 7$ & 2.82 & 2.77 & 1.00 & 0.00 & 1.44 & 0.17 & 7.12 & 5.16 & 0.15 & 0.00 & 0.32 & 0.00 \\
\hline$>\mathrm{C} 7$ & 0.00 & 5.05 & 0.00 & 6.40 & 0.00 & 8.12 & 0.00 & 0.00 & 0.00 & 0.00 & 0.00 & 0.00 \\
\hline
\end{tabular}


Table 5. Catalytic activity in the n-butene isomerisation for the high defect samples.

\begin{tabular}{|c|c|c|c|c|c|c|}
\hline \multirow{2}{*}{$\frac{\text { Samples }}{\text { Time (min.) }}$} & \multicolumn{2}{|c|}{ FER-bmp-quin-10d } & \multicolumn{2}{|c|}{ FER-bmp-quin-30d } & \multicolumn{2}{|c|}{ FER-bmp-TEA-11d } \\
\hline & 5 & 720 & 5 & 720 & 5 & 720 \\
\hline \multirow{2}{*}{$\begin{array}{l}\text { Conversion } \\
(\% \text { molar })\end{array}$} & 24.92 & 3.71 & 26.99 & 6.33 & 24.88 & 5.56 \\
\hline & \multicolumn{6}{|c|}{ Selectivity (\% molar) } \\
\hline C1 & 0.00 & 0.00 & 0.00 & 0.00 & 0.00 & 0.00 \\
\hline $\mathrm{C} 2$ & 0.00 & 0.00 & 0.00 & 0.00 & 0.00 & 0.00 \\
\hline $\mathrm{C} 2=$ & 0.74 & 0.00 & 1.36 & 0.00 & 0.86 & 0.00 \\
\hline $\mathrm{C} 3$ & 0.81 & 0.00 & 1.24 & 0.00 & 0.63 & 0.00 \\
\hline $\mathrm{C} 3=$ & 16.80 & 7.86 & 18.06 & 4.40 & 16.19 & 4.73 \\
\hline $\mathrm{I}-\mathrm{C} 4$ & 5.15 & 1.34 & 3.72 & 0.00 & 2.78 & 0.00 \\
\hline $\mathrm{N}-\mathrm{C} 4$ & 2.31 & 1.29 & 3.73 & 2.33 & 2.79 & 2.62 \\
\hline $\mathrm{I}-\mathrm{C} 4=$ & 42.45 & 70.23 & 44.11 & 79.18 & 45.13 & 75.58 \\
\hline C5 & 1.28 & 0.00 & 0.77 & 0.00 & 0.66 & 0.00 \\
\hline $\mathrm{C} 5=$ & 18.40 & 10.51 & 15.81 & 6.25 & 17.21 & 6.57 \\
\hline C6 & 3.44 & 0.00 & 3.04 & 0.00 & 2.98 & 0.00 \\
\hline C7 & 8.63 & 8.78 & 8.16 & 7.84 & 10.77 & 10.50 \\
\hline$>\mathrm{C} 7$ & 0.00 & 0.00 & 0.00 & 0.00 & 0.00 & 0.00 \\
\hline
\end{tabular}

